\title{
"ZooKids": um relato de atividade extensionista para o ensino da zootecnia a crianças
}

\author{
"ZooKids": an account of extension activity for the teaching of animal science \\ to children
}

\section{RESUMO}

Muitas crianças náo conhecem certos animais em função de viverem na cidade, portanto permitir o contato dessas crianças com animais da fazenda é proporcionar novas experiências, com novos cheiros, novas realidades e novos sons. Sabe-se que a estimulação precoce das crianças contribui para o seu aprendizado futuro, desenvolve suas capacidades motoras, afetivas e de relacionamento social. Neste relato, o objetivo é descrever a atividade de educação infantil voltada para o esclarecimento sobre a profissão do Zootecnista e a produção animal que foi desenvolvido em Lavras, Minas Gerais, no âmbito do projeto de extensão intitulado "ZooKids", realizado pelo grupo PET Zootecnia da Universidade Federal de Lavras. O projeto visa discutir o conhecimento sobre a criação animal e suas peculiaridades. A atividade foi desenvolvida no Departamento de Zootecnia, envolvendo setores de avicultura, cunicultura, ovinocultura e suinocultura. As crianças aprenderam sobre o correto manejo dos animais, como a alimentação é preparada, seu fornecimento e algumas características dentro de cada espécie visitada. Concluiu-se que a experiência foi satisfatória, verificando-se o relato das escolhas envolvidas ao projeto, além de relatos positivos por parte dos pais dos alunos que realizaram a visita ao departamento de Zootecnia da UFLA.

Palavras-chave: Criação animal. Ensino Fundamental. Esclarecimento. Zootecnia.

\section{ABSTRACT}

Many children do not know certain animals because they live in the city, thus, allowing these children to contact farm animals is to provide new experiences, with new smells, new colors and new sounds. It is known that the early stimulation of children contributes to their future learning, develops their motor, affective and social relationship skills. The objective of this report is to describe the child education activity aimed at clarifying the profession of Zootechnics and the animal production that was developed in Lavras, Minas Gerais, under the
Victor Hugo Silva Souza

Mestre em Engenharia Agrícola pela Universidade Federal de Lavras, Minas Gerais, Brasil (victorhssouza@hotmail. com).

Lívia Santos Figueiredo

Graduanda em Zootecnia na Universidade Federal de Lavras, Minas Gerais, Brasil; membro do Programa de Educação Tutorial Zootecnia (liviasfi@ hotmail.com).

Vitória Ferreira de Jesus

Graduanda em Zootecnia na Universidade Federal de Lavras, Minas Gerais, Brasil (vitoriaferreirazootecnia@ gmail.com)

Gleiton Tavares da Silva

Graduando em Zootecnia na Universidade Federal de Lavras, Minas Gerais, Brasil; membro do Programa de Educação Tutorial Zootecnia (gleitontavaresgts@gmail.com). 
extension project entitled "ZooKids", carried out by the group PET Zootecnia from the Federal University of Lavras. The project aims to offer knowledge about animal breeding and its peculiarities. The activity was developed in the Department of Animal Science, passing through the poultry, rabbit, sheep and swine sectors. The children learned about the correct management of the animals, how the food is formulated, their supply and some characteristics within each species visited. It was concluded that the experience was satisfactory, verifying the report of the choices involved in the project, as well as positive reports from the parents of the students who visited the Department of Animal Science.

Keywords: Animal breeding. Elementary School. Clarification. Animal Science.

\section{INTRODUÇÃO}

A criança e o adolescente gozam de todos os direitos fundamentais inerentes à pessoa humana, tendo assegurados, por lei ou por outros meios, todas as oportunidades e facilidades que lhes facultem o desenvolvimento físico, mental, moral, espiritual e social, em condições de liberdade e de dignidade (BRASIL, 1990).

A infância é um período de grande desenvolvimento físico marcado não somente pelo aumento do peso e altura, mas também pelas mudanças psicológicas e comportamentais que influenciam na formação de sua personalidade. Essa fase de desenvolvimento é também o momento de geração de conceitos e opinióes, motivado por um grande aporte de informaçóes que pode influenciar de modo positivo ou negativo a vida de crianças.

O contato delas com os educadores transforma-se em relaçóes de aprendizado. Cada criança tem seu jeito de ser, seus rituais e sua rotina. $\mathrm{O}$ processo de adaptação deve ocorrer com suavidade, sem rupturas bruscas, para que, aos poucos, ela possa ajustar-se ao grupo. Portanto, é importante que o educador também não se sinta ansioso, respeitando o tempo de cada um nesse processo.

Segundo Decroly (2010), as primeiras experiências de aprendizagem devem ser reais e concretas, passando-se depois ao mais abstrato. Por isso, o educador levou sua escola para os arredores da cidade, onde 
as crianças tinham mais contato com a natureza e com uma série de áreas externas em que podiam plantar, cuidar de animais e desenvolver muitas atividades ao ar livre.

Corroborando as ideias do estudioso belga, entendemos que os processos de adaptação entre a criança e o educador transformam as relaçóes de aprendizado mais práticas e atrativas, mostrando, de forma simples e educativa, o verdadeiro significado de algumas atividades realizadas nas diferentes criaçóes de animais - algo nunca visto pela maioria das crianças -, auxiliando na formação de novos cidadãos que, perante uma sociedade tão industrializada, deixaram de se sensibilizar com as etapas de formação dos produtos consumidos, sendo direcionados apenas ao mundo virtual de seus celulares e computadores.

Nesse intuito foi criado o projeto de extensão intitulado "ZooKids", realizado pelo grupo PET Zootecnia da Universidade Federal de Lavras (UFLA). O projeto foi desenvolvido para oferecer o conhecimento sobre a criação animal e suas peculiaridades. A atividade foi desenvolvida no Departamento de Zootecnia, passando pelos setores de avicultura, cunicultura, ovinocultura e suinocultura.

A extensão universitária nada mais é que a interação, a troca de conhecimentos entre a universidade e a comunidade na qual ela está inserida. Esse relacionamento é de suma importância para as duas partes envolvidas, visto que, em instituiçóes de ensino superior há pessoas de todas as partes do mundo, com culturas e costumes distintos da nova cidade.

A extensão envolve prestação de serviços e assistência à comunidade, possibilita à comunidade universitária conhecer problemáticas nacionais e atuar na busca de soluções plausíveis e facilita a integração ensino-pesquisa-extensão dentre outros. Não se pode ignorar a importância da extensão universitária na formação profissional e humana dos discentes envolvidos em açóes extensionistas diversas.

A troca de conhecimentos tem como objetivo principal levar à comunidade o conhecimento acadêmico; e a academia, por sua vez, é retroalimentada com os saberes comunitários. "A universidade ao comunicar-se com a realidade local, regional ou nacional tem a possibilidade de renovar constantemente sua própria estrutura, 
seus currículos e suas açôes, criativamente, conduzindo-os para o atendimento da verdadeira realidade do país" (SILVA OBERDAN, 1997).

\section{METODOLOGIAS QUALITATIVAS}

A utilização das metodologias qualitativas de investigação na forma de estudos de caso, etnográficos ou biográficos tem ganhado terreno na pesquisa em Ciências Sociais. As características de que se revestem tornam essas metodologias apropriadas a uma abordagem de processos socioculturais nas quais as interaçóes sociais constituem o objeto predominante e em que os sujeitos se assumem como agentes detentores de saberes (STAKE, 2009).

A interpretação da realidade, segundo a perspectiva dos autores Bogdan e Biklen (1994), é uma visão holista, assumindo que os sujeitos são capazes de "construir" a realidade e de refletir sobre a sua ação e criar uma visão sobre as coisas cheia de significados. A realidade é vista como ação culturalmente contextualizada e não como comportamentos predeterminados.

O conhecimento das características e dos fundamentos destas metodologias auxilia a estabelecer e a verificar o impacto que produzem na investigação social. Essas metodologias contribuem para superar a visão positivista da realidade sem deixar que o subjetivismo domine o campo da análise sociológica do real.

\section{Extensão para crianças}

Não basta aprender, pois o conhecimento é polivalente. Importa muito mais aprender a aprender e aprender a viver juntos, participar em projetos comuns. Aprender tornou-se, sobretudo, fazer uma grande viagem ao interior do ser, com autonomia, saber cuidar de si, dos outros, das coisas (GADOTTI, 2003).

A partir de Gadotti (2003), percebe-se a importância do aprender, que remete ao quanto é necessário trabalharmos em equipe, reconhecermos os deveres comuns e aplicá-los na sociedade. Deveres esses que podem ser trabalhados, incentivados por meios de projetos que utilizem da 
extensão como um meio de aprimorar o saber.

A extensão como atividade na vida de crianças e adolescentes se torna uma ferramenta que pode ser utilizada como um meio para promover práticas de trabalho em equipe, solidariedade e autonomia. Além de incentivar o desenvolvimento psicológico com métodos motivadores realizados em setores da sociedade pouco vistos por muitas dessas crianças.

A extensão está focada em atuar em áreas diferenciadas, gerando um conhecimento qualificado para quem a faz. Com isso, as crianças desfrutam de uma ampla variedade de alternativas acadêmicas e sociais, que influenciam diretamente em seu comportamento psicológico e social, além de promover uma melhor relação de interesse nas práticas escolares, auxiliando também no controle interdisciplinar dessas crianças.

\section{Contato de crianças com animais}

Desde os primórdios, o homem primitivo já convivia com animais. Os cães ofereciam proteção territorial nas cavernas contra invasores, além de ajudar nas caçadas. Hoje, além de segurança, essa relação homem-animal adiciona outras necessidades psicológicas.

O contato com animais pode ser benéfico para qualquer ser humano, mas é, especialmente, indicado para crianças. Buscando investigar qual a função do animal para a criança durante a infância, Levinson (1972), identificou-o como objeto de fantasia: um companheiro imaginário, um agente por meio do qual a criança aprende a ser responsável, a adquirir um sentido de identidade e a desenvolver independência.

Outras vantagens da relação animal-criança são apontadas por Garcia (2000), que mostra a importância do animal em ajudar a criança a: desenvolver a capacidade de se relacionar com outras pessoas e de lidar com aspectos não verbais; aprender a observar e interpretar a linguagem dos gestos, posturas e movimentos; favorecer a aprendizagem de fatos fundamentais da vida (como o nascimento, o crescimento, a reprodução e a morte); ajudar a desenvolver atitudes humanitárias em relação ao animal como ser vivo; despertar a consciência ecológica.

Para Faraco (2008), os animais podem proporcionar benefícios 
às crianças, tais como: companhia, promoção de mudanças positivas no autoconceito e comportamento das pessoas, além de auxiliar no desenvolvimento de várias habilidades e no exercício de responsabilidades. Os animais ajudam a diminuir o estresse e a combater a depressão e o isolamento.

Durante a realização do projeto, as crianças tiveram oportunidade de aprender um pouco mais sobre os animais, à medida que observavam e discutiam com o adulto e outras crianças sobre o comportamento animal em certas situaçóes. Puderam, ainda, identificar as características da raça (como hábitos e temperamento), suas necessidades e os cuidados que se deve ter com eles, conseguindo receber e dar afeição apropriada (DOTTI, 2005).

Vale ressaltar que, atualmente, é cada vez mais difícil para as crianças ter contato com animais no seu dia-a-dia, principalmente com animais domésticos de grande porte, como por exemplo, vaca, cavalo e porcos.

\section{Desenvolvimento do projeto}

Todos os animais do setor de Zootecnia da Universidade Federal de Lavras (UFLA) utilizados nesse projeto passaram obrigatoriamente por uma avaliação e atenderam aos requisitos de saúde animal, sendo avaliados, reavaliados e monitorados, antes do contato com as crianças do projeto.

O "Zookids" surgiu por meio do interesse das escolas de ensino fundamental do município de Lavras, Minas Gerais, por informações a respeito da criação e produção de animais domésticos. As escolas demonstraram interesse em apresentar aos alunos a UFLA, o Departamento de Zootecnia (DZO) e os sistemas de produção que a profissão contempla.

Foi criado um plano de requerimento de visitas de modo que atendesse a demanda e estivesse acessível a todas as instituiçóes interessadas. $\mathrm{O}$ projeto começou a ser desenvolvido no ano de 2017 e até a presente data já atendeu a mais de 10 escolas do município, dentre públicas e privadas.

O número de participantes do projeto já passou de 100 crianças e as perspectivas são de que esse número aumente, pois existe demanda 
para novas escolas realizarem a visita ao setor. Apesar de grande parte dos alunos visitantes estarem na faixa etária entre 4 e 6 anos, o projeto náo restringiu idade.

Para a realização das visitas, as turmas vinham acompanhadas de seus professores e eram recebidas pelos integrantes do Programa de Educação Tutorial do curso de Zootecnia da UFLA. Inicialmente ocorria uma apresentação dos petianos, que abordaram o que é a Zootecnia (Figura 1).

Figura 1 - Explicação sobre o curso de Zootecnia

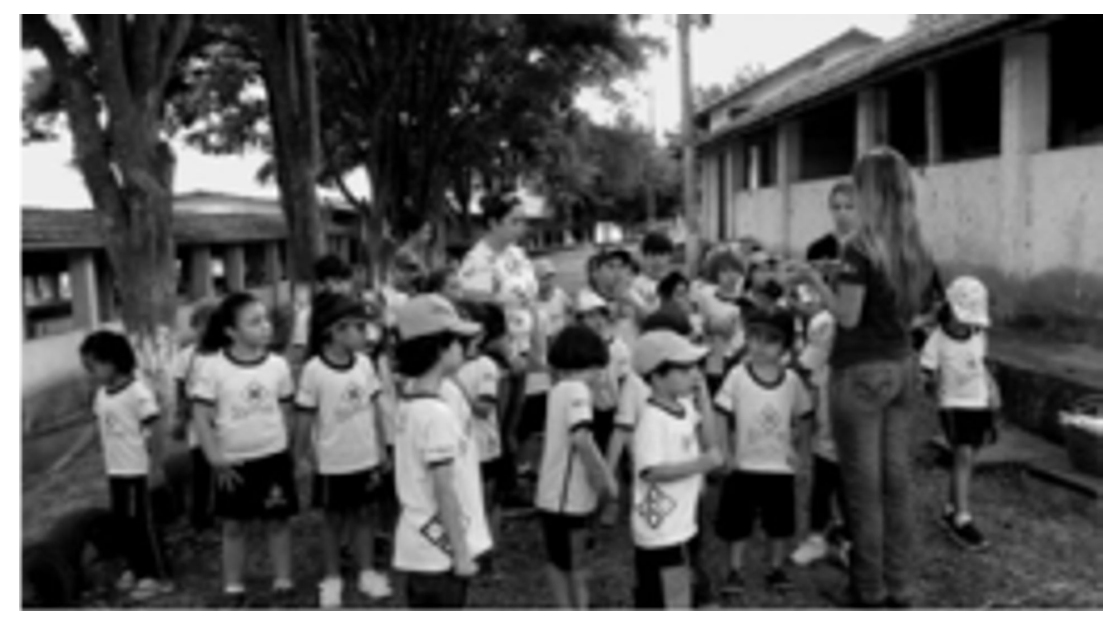

Fonte: Acervo do projeto (2018).

$\mathrm{O} \mathrm{DZO}$ e alguns setores do departamento foram apresentados de acordo com o tamanho da turma. Os setores visitados foram o de suinocultura, avicultura, ovinocultura e cunicultura.

$\mathrm{Na}$ suinocultura, foram apresentadas as diferentes fases de criação, passando pelo sistema de gestação coletiva, maternidade e creche. $\mathrm{Na}$ avicultura, foi apresentado um sistema de criação alternativo, em que os animais são criados soltos, e outro comercial, em que os animais são criados em galpóes. $\mathrm{Na}$ ovinocultura, foi mostrado que o animal não somente fornece lã para a fabricação de roupas, mas também carne para a nossa alimentação. Por último, foi apresentado o setor de cunicultura, no qual as crianças puderam ter o contato mais direto e mais afetivo com os coelhos, tocando e fazendo carinho nesses animais. 
De início, a reação principal das crianças foi de medo e surpresa com os animais, porém depois foram se mostrando mais receptivas e curiosas em relação à criação animal. As primeiras perguntas que surgiram por parte das crianças foram menos específicas, sempre tentando realçar alguma experiência anterior vivida por elas. Na continuação da visita, elas nos surpreenderam no final com dúvidas interessantes e mais focadas e uma boa assimilação das ideias, mostrando que já são aptas a acompanhar e continuar o raciocínio desde que bem transmitido.

Sempre na troca de setores era realizado um questionamento de maneira lúdica para verificar se houvera erros na comunicação e relembrar o que mais chamara a atenção das crianças em cada área da produção animal, trabalhando o melhoramento constante da comunicaçáo no projeto.

Algumas turmas voltaram outras vezes. Nesses casos, se buscou apresentar um novo setor, além de recapitular as informaçóes já passadas. As crianças, no desenvolvimento da visita, demonstravam cada vez mais respeito pelos animais e sinalizavam admiraçáo e entusiasmo pela profissão do Zootecnista e demais trabalhadores.

Por meio de metodologias qualitativas, pudemos verificar que as crianças conseguiram construir o conhecimento sobre a Zootecnia e conseguiram refletir sobre os diferentes sistemas de criação, a importância do bem estar animal e o fornecimento de alimentos em quantidade e qualidade ideais para a criação desses animais.

Como indicadores de avaliação do trabalho, ao final da visita ao setor de Zootecnia, foi pedido para as crianças que confeccionassem três desenhos: o primeiro sobre a profissáo do Zootecnista, o segundo sobre os alimentos que eram fornecidos a esse animal; e o terceiro sobre o animal de que mais gostaram (Figura 2). Com isso, obtivemos um indicativo de aprendizado das crianças sobre todo o conteúdo informado e com que animal as crianças mais se identificaram. 
Figura 2 - Desenho de uma das crianças do projeto

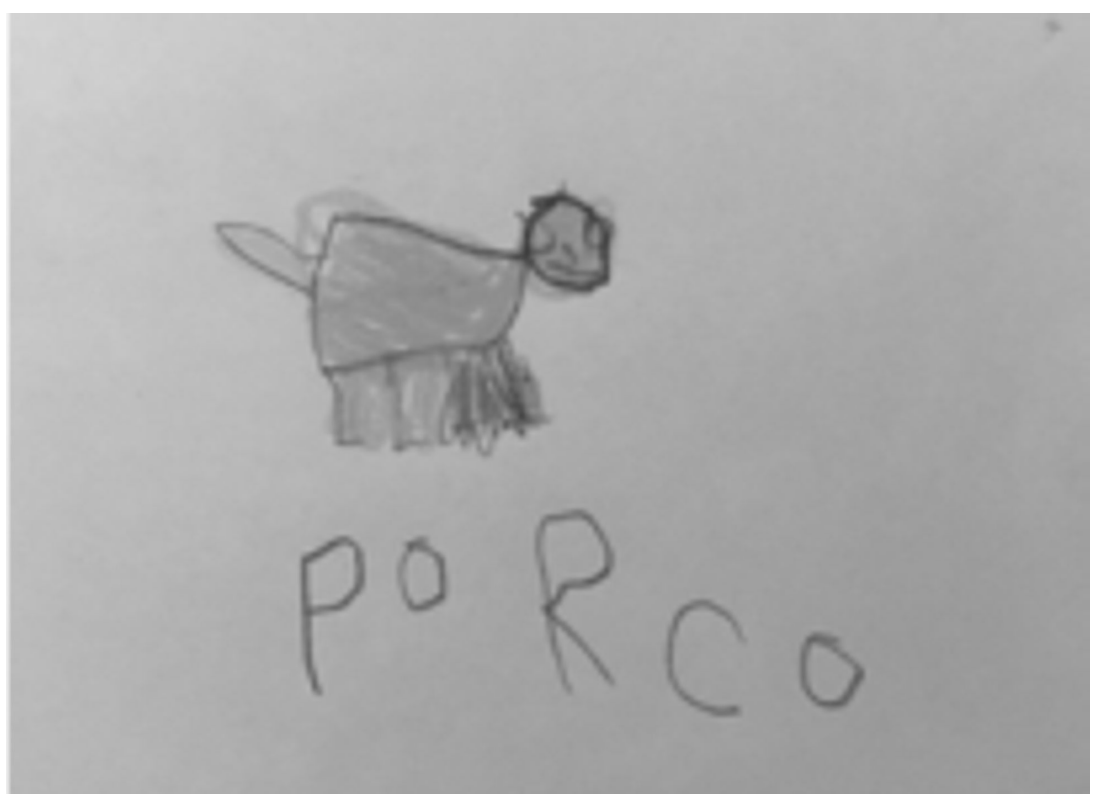

Fonte: Acervo do projeto (2018).

\section{CONSIDERAÇÕES FINAIS}

As crianças passaram a interagir mais com os professores e colegas de turma após a visita aos animais, demonstrando menor timidez, expressando-se mais facilmente e participando mais intensamente das atividades desenvolvidas em sala de aula. O diálogo das crianças com os pais também foi percebido, decorrente da empolgação delas em contar suas novas experiências com os animais.

O reconhecimento da importância de diversas profissóes é fundamental para a formação de pessoas mais sensatas e respeitosas, as quais aprendem a admirar o trabalho em diferentes cadeias de produção. A produção animal vista de forma esclarecida desde cedo proporciona um mercado consumidor mais crítico a possíveis alienaçôes como também a valorização dos alimentos. 


\section{AGRADECIMENTOS}

Ao MEC por proporcionar a manutençáo do grupo PET-Zootecnia. Às crianças, professores e diretores que prestigiaram o projeto. À Universidade Federal de Lavras, em especial o Departamento de Zootecnia e seu corpo docente.

\section{REFERÊNCIAS}

BOGDAN, R.; BIKLEN, S. Investigaçáo qualitativa em educaçáo. Porto: Porto Editora, 1994. 336 p.

DECROLY, J. O. Textos selecionados. In: DUBREUCQ, F. Jean-Ovide Decroly. Tradução de Carlos Alberto Vieira Coelho, Jason Ferreira Mafra, Lutgardes Costa Freire, Denise Henrique Mafra. Recife: Fundação Joaquim Nabuco, 2010. 156 p. (Coleção Educadores).

DOTTI, J. Terapia e animais: atividade e terapia assistida por animais - práticas para organizaçóes, profissionais e voluntários. São Paulo: PC Editorial, 2005.

BRASIL. Estatuto da Criança e do Adolescente, 1990. Lei No 8.069, de 13 de julho de 1990. Dispóe sobre o Estatuto da Criança e do Adolescente e dá outras providências. Brasília, DF, 1990.

FARACO, C. B. Interação humano-animal. Ciência veterinária nos trópicos, Recife, v. 11. p. 31-35, abr. 2008. Disponível em: <http:// www.rcvt.org.br/suplemento11/31-35.pdf>. Acesso em: 10 maio 2018.

FIGUEIREDO, M. do A. C de. et al. Metodologia de oficina pedagógica: uma experiência de extensão com crianças e adolescentes. Extensáo Cidadá, João Pessoa, v. 2, p. 1-12, 2006.

GADOTTI, M. Saber aprender: um olhar sobre Paulo Freire e as perspectivas atuais da educação. In: CONGRESSO INTERNACIONAL, 1., 2000, Anais... Évora: Editora da Universidade de Évora, 2000.

GARCIA, A. O emprego de animais na terapia infantil. Pediatria 
Moderna, São Paulo, v. 26, p. 75-79, 2000.

LEVINSON, B. M. Pets and human development. Springfield, Illinois: Charles C. Tomas, 1972.

STAKE, R. E. A arte da investigaçáo com estudos de caso. Lisboa: Calouste Gulbenkian, 2009.

Submetido em 10 de julho de 2018.

Aprovado em 15 de outubro de 2018. 